\title{
Avaliação da morfologia de oócitos imaturos de bovinos criopreservados em diferentes concentrações de 1,2 propanediol
}

\section{Morphological evaluation of immature bovine oocytes cryopreservated with 1,2 propanediol}

\author{
Wanderlei Ferreira de Sá, ${ }^{\star}$ Luiz Sérgio de Almeida Camargo, ${ }^{* *}$ Ademir de Moraes Ferreira, ${ }^{*}$ \\ Flamarion Tenório Albuquerque, ${ }^{\star \star \star}$ Luiz Altamiro Garcia Nogueira ${ }^{\star \star \star \star}$
}

\begin{abstract}
Resumo
O objetivo deste trabalho foi estudar a morfologia de oócitos imaturos de bovinos abatidos em matadouro, frente à criopreservação clássica com dois gradientes de concentração diferentes de crioprotetor. No tratamento 1, utilizou-se $1,6 \mathrm{M}$ de 1,2 propanediol, onde os oócitos foram desidratados em 3 etapas crescentes $(0,53 ; 1,06$ e 1,6M), à temperatura ambiente e congelados utilizando-se o método clássico. A descongelação foi realizada em banho Maria a $37^{\circ} \mathrm{C}$ por 30 " e reidratação em três etapas decrescentes $(1,6 ; 1,06$ e 0,53M), acrescidos de 0,25M de sacarose cada. No tratamento 2 foi utilizado 2,0M de 1,2 propanediol, de maneira semelhante ao tratamento 1, com desidratação contendo 0,7; 1,4 e 2,0M e reidratação 2,0; 1,4 e 0,7M. Após a reidratação os oócitos foram lavados em meio TCM 199 e levados para maturação in vitro. O grupo controle foi constituído de oócitos recém-colhidos, colocados para maturação por $24 \mathrm{~h}$ em meio TCM $199 \mathrm{com} 10 \%$ de SVC e FSH em co-cultura, com $5 \% \mathrm{CO}_{2}$ no ar a $39^{\circ} \mathrm{C}$. Os resultados foram semelhantes $(\mathrm{P}>0.05)$ para as duas concentrações de propanediol utilizadas, após a descongelação e reidratação sendo que $69,5 \%(n=308)$ dos oócitos apresentaram morfologia considerada normal, 5,2\% ( $n=308)$ de desnudos e 25,3\% $(n=308)$ de degenerados. Entretanto, após maturação in vitro, 19,15\% $(n=308)$ oócitos apresentaram rompimento da "zona pelúcida".
\end{abstract}

Palavras-chave: bovinos; oócitos; criopreservação; morfologia.

\section{Introdução}

A fecundação in vitro (FIV) é uma técnica que permite o aproveitamento de um número maior de oócitos do que a transferência de embriões por superovulação, favorecendo o melhoramento genético através do aumento da intensidade de seleção e diminuição do intervalo entre gerações, além de propiciar estudos relacionados com a interação de gametas e engenharia genética.

O aproveitamento de gametas femininos para a FIV implica também a necessidade do desenvolvimento de técnicas para a conservação dos mesmos. Com a criopreservação de oócitos, pode-se formar bancos de gametas femininos, para serem utilizados em pesquisa ou em aplicações comerciais e para a preservação de espécies em extinção, contribuindo, juntamente com a FIV, para o melhoramento genético e para o desenvolvimento de técnicas relacionadas à clonagem e engenharia genética. Dessa maneira estudos têm sido realizados para a criopreservação de oócitos.
Procedimentos para a criopreservação de oócitos não têmse desenvolvido na mesma extensão que ocorreu com os embriões. No entanto, com o estabelecimento das técnicas de FIV, houve um incremento nestes estudos.

Um ponto importante na criopreservação de oócitos imaturos é a manutenção da sua capacidade de desenvolvimento após a descongelação. Em oócitos imaturos recém-aspirados, existe uma relação entre a sua morfologia e a capacidade de maturar in vitro (Sirard et al., 1992), tornando importante esta avaliação morfológica para a seleção dos oócitos. Outro aspecto na congelação de oócitos imaturos é a manutenção das células do cumulus. Essas células podem intermediar ou produzir diversos fatores que interferem na maturação e subsequente desenvolvimento do zigoto (Brackett e Zuelke, 1993; Thibault et al., 1987). As células do cumulus podem propiciar um acúmulo de energia suficiente para permitir a fecundação e desenvolvimento embrionário inicial, até que o genoma embrionário torne-se ativo (Sirard et al., 1992). Desse modo, a presença das células do cumulus após a descongelação é importante para o posterior desenvolvimento do gameta.

\footnotetext{
${ }^{\star}$ Embrapa - Gado de Leite. Rua Eugênio do Nascimento,610, 36038-330 Dom Bosco - Juiz de Fora/MG, Brasil .

${ }^{* *}$ Médico Veterinário, bolsista CAPES, Embrapa - Gado de Leite.

*** Departamento de Zootecnia, Universidade Federal Rural do Rio de Janeiro (UFRRJ), Rod. Antiga Rio-São Paulo, Km 47, Seropédica, RJ, Brasil.

${ }^{\star \star * *}$ Faculdade de Veterinária, DS, Universidade Federal Fluminense (UFF), Rua Vital Brazil Filho 64, 24230-340 Niterói/RJ, Brasil.
} 
Um dos métodos mais utilizados para a criopreservação, tanto para embriões como para oócitos bovinos, é o clássico, que possui uma curva de congelação lenta. Entre os crioprotetores, os mais utilizados têm sido o glicerol, propanediol $(\mathrm{PROH})$ e o dimetil sulfóxido (DMSO). A utilização desses crioprotetores tem produzido resultados inconsistentes quando utilizados na FIV (Fuku et al., 1992 ; Schellander et al., 1994 ;Yang et al., 1994). Quando compararam diversos crioprotetores, Suzuki e Nishikata (1992) citaram que o $\mathrm{PROH}$ pode ser um crioprotetor mais apropriado para a congelação de oócitos imaturos de bovinos. No entanto, Schellander et al. (1994) não observaram diferenças nas taxas de clivagem quando utilizaram glicerol, PROH e DMSO. Os crioprotetores também possuem toxicidade química, que pode causar danos ao citoesqueleto das células (Parks e Ruffing, 1992).

Desse modo, este trabalho tem o objetivo de estudar o efeito de duas concentrações de $\mathrm{PROH}$ pela congelação clássica, sobre a morfologia de oócitos imaturos de bovinos.

\section{Material e métodos}

Os oócitos foram aspirados de ovários de fêmeas bovinas mestiças, colhidos em matadouro distante $35 \mathrm{~km}$ do laboratório. Os ovários foram transportados acondicionados em frascos com solução fisiológica $(0,9 \% \mathrm{NaCl})$ contendo antibióticos $(0,1 \mathrm{~g} / \mathrm{I}$ de sulfato de estreptomicina), em temperatura entre 30 e $34^{\circ} \mathrm{C}$, por um período de 3 horas após a coleta. $O$ experimento foi conduzido de janeiro a julho de 1995, no Laboratório de Reprodução Animal da EMBRAPA - Centro Nacional de Pesquisa de Gado de Leite, Coronel Pacheco, MG.

Dos ovários colhidos, foram puncionados folículos de diâmetro acima de $1,5 \mathrm{~mm}$ e o conteúdo foi depositado em um cálice cônico contendo meio Talp Hepes (Bavister et al., 1983), previamente aquecido a $37^{\circ} \mathrm{C}$. Após um período de decantação de 10 minutos, o sobrenadante foi desprezado e o sedimento foi lavado com meio Talp Hepes e depositado em uma placa de Petri mantida em placa aquecedora a $38^{\circ} \mathrm{C}$, para a manipulação dos oócitos. Os oócitos foram lavados por duas vezes em meio Talp Hepes e, em seguida, avaliados morfologicamente. Os oócitos contendo células do cumulus oofhorus compacto, com no mínimo 3 camadas (complexo oócito-cumulus; COC) e citoplasma homogêneo foram classificados como viáveis e selecionados para o experimento.

Os oócitos viáveis foram divididos em dois tratamentos e um grupo controle. Todos os oócitos foram congelados com suas respectivas células do cumulus.

O meio utilizado para congelar e descongelar foi o TCM 199 , acrescido de 0,4\% de albumina sérica bovina. Os tratamentos utilizados para este experimento foram os seguintes:

\section{Tratamento 1}

Foram avaliados $136 \mathrm{COC}$, congelados em 1,6 M de PROH pelo método clássico (Rodrigues, 1992). Logo após a lavagem dos COC em Talp Hepes, estes foram desidratados em três banhos (etapas), com quantidades crescentes do crioprotetor, em dez minutos cada etapa, em temperatura ambiente (aproximadamente $25^{\circ} \mathrm{C}$ ), conforme segue:

$1^{\text {a }}$ etapa: $0,53 \mathrm{M}$ de $\mathrm{PROH}$

$2^{\mathrm{a}}$ etapa: $1,06 \mathrm{M}$ de $\mathrm{PROH}$

$3^{\text {a }}$ etapa: $1,6 \mathrm{M}$ de $\mathrm{PROH}$

Antes de completar a terceira etapa, os COC foram envasados em palhetas de $0,25 \mathrm{ml}$. Ao término desta etapa foram levados à máquina de congelação (BIO-COOL ${ }^{T M}$, FTS Systems Inc., modelo BC-70-4A), previamente resfriada a $-7^{\circ} \mathrm{C}$, onde permaneceram por dez minutos para a estabilização, realizando-se logo em seguida o seeding, seguido de mais cinco minutos para nova estabilização. Após este período, a temperatura desceu de -7 para $-32^{\circ} \mathrm{C}$ a uma velocidade de $0.5^{\circ} \mathrm{C} / \mathrm{min}$, atingindo $-32^{\circ} \mathrm{C}$, as palhetas foram mergulhadas em nitrogênio liquido $\left(-196^{\circ} \mathrm{C}\right)$. Estas palhetas foram conservadas em nitrogênio líquido por, no mínimo, uma semana.

A descongelação foi realizada em água a $37^{\circ} \mathrm{C}$ por trinta segundos, e a reidratação em temperatura ambiente, em três banhos (etapas) com quantidades decrescentes do crioprotetor, adicionados de 0,25 $\mathrm{M}$ de sacarose, com 7 minutos de duração para cada etapa, conforme indicado a seguir:

$1^{\text {a }}$ etapa: $1,6 \mathrm{M}$ de $\mathrm{PROH}+0,25 \mathrm{M}$ de sacarose

$2^{\text {a }}$ etapa: $1,06 \mathrm{M}$ de $\mathrm{PROH}+0,25 \mathrm{M}$ de sacarose,

$3^{\text {a }}$ etapa: $0,53 \mathrm{M}$ de $\mathrm{PROH}+0,25 \mathrm{M}$ de sacarose

\section{Tratamento 2}

Foram avaliados $172 \mathrm{COC}$ congelados em 2,0 M de PROH, pelo método clássico (RODRIGUES, 1992). A desidratação foi realizada da mesma maneira do tratamento 1 , contendo apenas concentrações diferentes do crioprotetor, que foram as seguintes:

\section{$1^{\text {a }}$ etapa: $0,7 \mathrm{M}$ de PROH \\ $2^{\text {a }}$ etapa: $1,4 \mathrm{M}$ de $\mathrm{PROH}$ \\ $3^{\text {a }}$ etapa: 2,0 $\mathrm{M}$ de $\mathrm{PROH}$}

A curva de congelação foi a mesma do tratamento 1, assim como a descongelação e reidratação, com as seguintes concentrações do crioprotetor:

$1^{\text {a }}$ etapa: $2,0 \mathrm{M}$ de $\mathrm{PROH}+0,25 \mathrm{M}$ de sacarose

$2^{\text {a }}$ etapa: $1,4 \mathrm{M}$ de $\mathrm{PROH}+0,25 \mathrm{M}$ de sacarose

$3^{\text {a }}$ etapa: 0,7 M de $\mathrm{PROH}+0,25 \mathrm{M}$ de sacarose

Logo após a reidratação, os COC, de ambos os tratamentos, foram lavados duas vezes em meio TCM 199 (COSTA et al., 1994). Após as lavagens, todos os COC foram colocados para maturar in vitro. 


\section{Controle}

Constituído de 131 COC não congelados (frescos), que foram levados para a maturação in vitro logo após a seleção.

A maturação in vitro, para os tratamentos e controle, foram realizados em placas de Petri de $35 \mathrm{~mm}$ de diâmetro, contendo 3ml de TCM 199, conforme Costa (1994), para se avaliar as alterações morfológicas provocadas pela congelação, após esse procedimento. Os cultivos foram realizados em estufa incubadora (NAPCO, modelo 6100) a $39^{\circ} \mathrm{C}$, em atmosfera de $5 \%$ de $\mathrm{CO}_{2}, 95 \%$ de ar atmosférico e $95 \%$ de umidade por 24 horas.

A avaliação da morfologia dos oócitos foi realizada após descongelação/reidratação e maturação in vitro, baseando-se nas condições das células do cumulus e a aparência do citoplasma. Na avaliação após a descongelação/ reidratação, os $\mathrm{COC}$ foram classificados em $\mathrm{COC}$ normais (com células do cumulus aderidas, compactas e homogêneas e oócitos com citoplasma homogêneo e sem fragmentação), oócitos desnudos (sem a presença das células do cumulus); degenerados ou com rompimento da zona pelúcida. A avaliação após a maturação in vitro considerou a expansão e aderência das células do cumulus, e integridade da zona pelúcida (após desnudamento realizado com uma pipeta de 100 $\mu$ l).

Foram realizadas três repetições para cada tratamento. Os dados obtidos foram analisados pelo teste do Qui Quadrado (Gomes, 1977).

\section{Resultados e discussão}

Os resultados da congelação, descongelação e reidratação sobre a morfologia dos COC estão apresentados na Tabela 1. A porcentagem de oócitos com morfologia normal foi semelhante entre os dois tratamentos, assim como a de oócitos desnudos $(p>0,05)$. Os oócitos considerados degenerados apresentaram o citoplasma menos denso e com textura irregular, e alguns ainda apresentavam o espaço perivitelino aumentado (Figura 1). Não foi observado rompimento da zona pelúcida (ZP) após o descongelamento e reidratação.

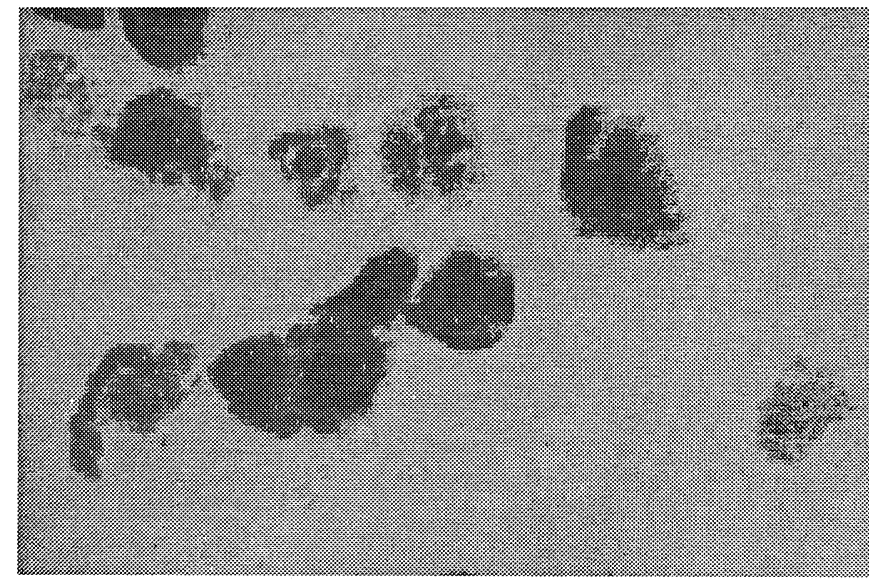

Figura 1: Oócitos imaturos bovinos logo após a descongelação e reidratação, apresentando morfologia considerada anormal (40x)

Não se observou diferença entre as congelações realizadas com 1,6 M ou com 2,0 M de PROH na morfologia dos COC, produzindo um total de $69,5 \%$ de COC com aparência morfológica normal. Essa taxa é superior aos $33,3 \%$ de COC imaturos normais de bovinos encontrados por Lim et al. (1992) e aos 30,7\% de COC verificados por Fuku et al. (1992).

Entretanto, os resultados são inferiores aos $78,1 \%$ obtidos por De Bem et al. (1993), e aos $80,9 \%$ observados por Yang et al. (1994), ambos utilizando PROH. Schellander et al. (1994) observaram 95\% de aparência morfológica normal em COC imaturos congelados pelo método clássico com glicerol, PROH e DMSO, mas após a maturação in vitro apenas $38 \%$ permaneceram intactos.

Após a maturação in vitro, houve a expansão de todas as células do cumulus que estavam presentes nos oócitos, semelhante ao grupo controle. Isto indica que essas células mantiveram sua viabilidade após a criopresenvação, confirmando Didion et al. (1990), que observaram que as células do cumulus de oócitos imaturos de suínos sobrevivem à congelação, e Yang et al. (1994), que encontraram 60\% de expansão das células do cumulus após a

Tabela 1: Efeito da criopreservação com PROH sobre a morfologia dos oócitos bovinos, logo após a descongelamento e reidratação

\begin{tabular}{ccccc}
\hline Tratamento & $\mathrm{n}$ & $\begin{array}{c}\text { Número de COC com } \\
\text { morfologia normal }(\%)\end{array}$ & $\begin{array}{c}\text { Número de oócitos } \\
\text { desnudos }(\%)\end{array}$ & $\begin{array}{c}\text { Número de oócitos } \\
\text { degenerados (\%) }\end{array}$ \\
\hline $0,53-1,6 \mathrm{M} \mathrm{PROH}$ & 136 & $97(71,32)$ & $11(8,1)$ & $28(20,5)$ \\
$0,70-2,0 \mathrm{M} \mathrm{PROH}$ & 172 & $117(68,0)$ & $5(2,9)$ & $50(29,1)$ \\
\hline Total & 308 & $214(69,5)$ & $16(5,2)$ & $78(25,3)$ \\
\hline
\end{tabular}

As diferenças observadas entre os tratamentos não foram significativas $(p>0,05)$. 
descongelação, quando utilizaram $\mathrm{COC}$ de bovinos. Entretanto, apesar de poucos oócitos apresentarem-se desnudos durante a descongelação e reidratação, as células do cumulus mostraram-se fracamente aderidas após a maturação in vitro, o que foi observado durante a manipulação e no processo de desnudamento, ao serem facilmente destacadas, ao contrário dos oócitos no grupo controle. Isto pode implicar insuficiente comunicação entre as células do cumulus e oócito, interrompendo o transporte de metabólitos entre essas duas células, alterando a atividade metabólica do oócito. Provavelmente, este fato pode prejudicar a maturação e principalmente, a fecundação in vitro e o futuro desenvolvimento da célula após a fecundação. Schroeder et al. (1990) postulam que lesões nas células do cumulus durante a congelação podem tornar os oócitos deficientes para suportar a maturação in vitro e diminuir a sobrevivência pós-descongelação.

Apesar de não ter sido observado rompimento da ZP na descongelação e reidratação, esta ocorreu após a maturação in vitro e procedimentos de manipulação para desnudamento, em ambos os tratamentos (Tabela 2). Nos oócitos do grupo controle não ocorreu rompimento da ZP. Grande parte desse rompimento pode ter ocorrido nos oócitos que se apresentaram degenerados após a descongelação. Entretanto, não houve diferença entre os tratamentos. Este fato mostra um enfraquecimento da ZP ou alteração de seus constituintes durante a congelação e descongelação, mas que não foi suficiente para rompê-la durante essas fases. Estas lesões são confirmadas por Yang et al. (1994) e Schmidt et al. (1995) em oócitos criopreservados, através de microscopia eletrônica.

A taxa total de ZP rompida deste experimento $(19,15 \%)$, encontrado após a maturação in vitro e desnudamento, foi inferior aos 27,8\% obtidos por De Bem et al. (1993). Entretanto, esse rompimento ocorreu na descongelação de oócitos imaturos desnudos de bovinos. Talvez a presença das células do cumulus possa ter um papel de proteção para a ZP durante a congelação e descongelação.

Tabela 2: Número de oócitos descongelados apresentando zona pelucida intacta ou rompida, após a maturação in vitro e desnudamento

\begin{tabular}{cccc}
\hline Tratamento & $\mathrm{n}$ & $\begin{array}{c}\text { Número de oócitos com zona } \\
\text { pelúcida intacta }(\%)\end{array}$ & $\begin{array}{c}\text { Número de oócitos com zona } \\
\text { pelúcida rompida (\%) }\end{array}$ \\
\hline $0,53-1,6 \mathrm{M} \mathrm{PROH}$ & 136 & $109(80,15)$ & $27(19,85)$ \\
$0,70-2,0 \mathrm{M} \mathrm{PROH}$ & 172 & $140(81,40)$ & $32(18,60)$ \\
\hline Total & 308 & $249(80,85)$ & $59(19,15)$ \\
\hline
\end{tabular}

As diferenças observaadas entre os tratamentos não foram significativas $(p>0,05)$.

\section{Conclusões}

1 As diferenças observadas entre os tratamentos 1 e 2 não foram estatisticamente significativas, indicando não haver diferença entre os gradientes de concentração de $\mathrm{PROH}$ estudados sobre a morfologia de oócitos imaturos.

2 As diferentes concentrações de $\mathrm{PROH}$ estudadas não afetam a permanência das células do cumulus, porém diminuem o grau de aderência destas ao oócito.
3 A criopreservação das células do cumulus junto aos oócitos resultou em uma proteção maior à zona pelúcida, pois não foi observado rompimento desta após descongelação. No entanto, suas propriedades físicas foram afetadas pois estavam mais susceptíveis a danos físicos, o que foi observado durante desnudamento, após a maturação in vitro.

4 Em virtude dos resultados observados quanto a morfologia dos COC imaturos criopreservados, estudos devem ser conduzidos para verificar a viabilidade desses após os processos de maturação e fecundação in vitro.

\begin{abstract}
A study was carried out to investigate the morphology of immature bovine cumulus-oocytes complexes following standard cryopreservation in two different levels of propanediol $(\mathrm{PROH})$. Treatment 1 consisted of subjecting oocytes to a gradual 3-step, concentration-driven dehydration with $\mathrm{PROH}(0.53 ; 1.06$ and $1.6 \mathrm{M})$ at room temperature and subsequent freezing by the standard procedure. Oocytes were thawed in water at $37^{\circ} \mathrm{C}$ for $30^{\prime \prime}$ and subjected to a gradual 3 -step, concentrationdriven rehydration with $\mathrm{PROH}(1.6 ; 1.06$ and $0.53 \mathrm{M})$ in the presence of $0.25 \mathrm{M}$ sucrose. Treatment 2 was conducted the same way, but PROH concentrations for dehydration were $0.7 ; 1.4$ and $2.0 \mathrm{M}$ and for rehydration were 2.0; 1.4 and
\end{abstract}


0.7M. After rehydration, oocytes of both treatments were washed in TCM 199 medium, followed by the in vitro maturation. The control consisted of nonfrozen oocytes. Oocytes were cultured in TCM 199 medium with $10 \% \mathrm{ECS}, \mathrm{FSH}, 5 \% \mathrm{CO}_{2}$ air in co-culture at $39^{\circ} \mathrm{C}$, for $24 \mathrm{~h}$. The following caracteristics were similar for treatment 1 and 2 after thawing and rehydration: oocyte with normal morphology $(69,48 \%, n=308)$, denuded $(5,2 \%, n=308)$ and degenerate $(25,3 \% ; n=308)$. However, after in vitro maturation $19,15 \%(n=308)$ oocytes were with rupture of zona pelucida.

Keywords: bovine, oocyte, cryopreservation, morphology.

\section{Referências bibliográficas}

BAVISTER, B.D, LEIBFRIED, M.L., LIEBERMAN, G. Development of preimplantation embryos of the Golden hamster in a defined culture medium. Biology of Reproduction, Champaign, v. 28, p. 235-243, 1983.

BRACKETT, B.G., ZUELKE, K.A. Analysis of factors involved in the vitro production of bovine embryos. Theriogenology, Stoneham, v. 39, p. 43-64, 1993.

COSTA, E.P. Aspectos morfológicos (citológicos e ultraestruturais) e desenvolvimento de ovócitos de bovinos in vitro. 1994. $155 \mathrm{f}$. Tese (Doutorado)- Escola de Veterinária, UFMG, 1994.

COSTA, E.P, VALE FILHO, V.R., NOGUEIRA, J.C. et al. Cultivo in vitro de ovócitos de bovinos em diferentes sistemas. IEfeito na maturação nuclear. In: ENCONTRO DE PESQUISA DA ESCOLA DE VETERINÁRIA, 14., 1994, Belo Horizonte. Anais... Belo Horizonte : UFMG, 1994. p. 70.

DeBEM, A.R., FREITAS, V.C., SOUSA, R.V. et al. Cryopreservation of immature oocyte of bovine using 1.2 propanediol and glycerol as cryoprotector. In: RÉUNION ASSOCIATION EUROPEENNE DE TRANSFERT EMBRYONNAIRE, 9., 1993, Lyon. Anais... Lyon : [s.n.], 1993. p. 184.

DIDION, B.A., POMP, D., MARTIN, M.J. et al. Observations on the cooling and cryopreservation of pig oocytes at the germinal vesicle stage. Journal of Animal Science, Champaign, v. 68, p. 2803-2810, 1990.

FUKU, E., KOJIMA, T., SHIOYA, Y. et al. In vitro fertilization and development of frozen-thawed bovine oocytes. Cryobiology, San Diego, v. 29, p. 485-492, 1992.

GOMES, F.P. Curso de estatística experimental. 7. ed. Piracicaba : Nobel,1977. 430 p.

LIM, J.M, FUKUI, Y., ONO, H. Developmental competence of bovine oocytes frozen at various maturation stage followed by in vitro maturation and fertilization. Theriogenology, Stoneham, v. 37, p. 351-361, 1992.
PARKS, J.E., RUFFING, N.A. Factors affecting low temperature survival of mammalian oocytes. Theriogenology, Stoneham, v. 37, p. 59-73, 1992.

RODRIGUES, J.L. Aspectos da congelação de embriões bovinos. In: REUNIÃO DA SOCIEDADE BRASILEIRA DE TRANSFERÊNCIA DE EMBRIÕES, 7., 1992, Jaboticabal. Anais... Jaboticabal : [s.n.], 1992. p. 55-79.

SCHELLANDER, K, PELI, J., SCHMOLL, F. et al. Effects of different cryoprotectants and carbohydrates on freezing of matured and unmature bovine oocytes. Theriogenology, Stoneham, v. 42, p. 909-915, 1994.

SCHMIDT, M., HYTTEL, P., AVERY, B. et al. Ultrastructure of in vitro matured bovine oocytes after controlled freezing in 10\% glycerol. Animal Reproduction Science, Amsterdam, v. 37, p. 281-290, 1995.

SCHROEDER, A.C., CHAMPLIN, A.K., MOBRAATEN, L.E. et al. Development capacity of mouse oocytes cryopreserved before and after maturation in vitro. Journal of Reproduction and Fertility, Cambridge, v. 89, p. 43-50, 1990.

SIRARD, M.A., COENEN, K., BILODEAU, S. Effect of fresh or cultured follicular fractions on meiotic resumption in bovine oocytes. Theriogenology, Stoneham, v. 37, p. 39-57, 1992.

SUZUKI, T., NISHIKATA, Y. Fertilization and cleavage of frozen thawed bovine oocytes by one step diluition method in vitro. Theriogenology, Stoneham, v. 37, p. 306, 1992.

THIBAULT, C., SZOLLOSI, D., GÉRARD, M. Mammalian oocyte maturation. Reproduction Nutrition and Development, Paris, v. 27, p. 865-896, 1987.

YANG, Q.Z., SUN, Q.Y., LIU, G.Y. et al. Developmental competence and ultrastructure damage of cryopreserved G.V. stage bovine oocytes. Theriogenology, Stoneham, v. 41, p. 342, 1994. 